\title{
Minimally invasive surgical treatment of intracranial meningiomas in elderly patients ( $\geq 65$ years): outcomes, readmissions, and tumor control
}

\author{
Jai Deep Thakur, MD, ${ }^{1-3}$ Regin Jay Mallari, BS, ${ }^{1}$ Alex Corlin, BA,, Samantha Yawitz, ${ }^{1}$ \\ Weichao Huang, MD, ${ }^{1}$ Amy Eisenberg, MSN, ARNP, CNRN, ${ }^{1}$ Walavan Sivakumar, MD, ${ }^{1,2}$ \\ Howard R. Krauss, MD,1,2 Chester Griffiths, MD, 1,2 Garni Barkhoudarian, MD,1,2 \\ and Daniel F. Kelly, MD ${ }^{1,2}$
}

1Pacific Neuroscience Institute, and 2John Wayne Cancer Institute, Providence Saint John's Health Center, Santa Monica, California; and ${ }^{3}$ University of South Alabama, Mobile, Alabama

OBJECTIVE Increased lifespan has led to more elderly patients being diagnosed with meningiomas. In this study, the authors sought to analyze and compare patients $\geq 65$ years old with those $<65$ years old who underwent minimally invasive surgery for meningioma. To address surgical selection criteria, the authors also assessed a cohort of patients managed without surgery.

METHODS In a retrospective analysis, consecutive patients with meningiomas who underwent minimally invasive (endonasal, supraorbital, minipterional, transfalcine, or retromastoid) and conventional surgical treatment approaches during the period from 2008 to 2019 were dichotomized into those $\geq 65$ and those $<65$ years old to compare resection rates, endoscopy use, complications, and length of hospital stay (LOS). A comparator meningioma cohort of patients $\geq$ 65 years old who were observed without surgery during the period from 2015 to 2019 was also analyzed.

RESULTS Of 291 patients (median age 60 years, $71.5 \%$ females, mean follow-up 36 months) undergoing meningioma resection, $118(40.5 \%)$ were aged $\geq 65$ years and underwent 126 surgeries, including $20 \%$ redo operations, as follows: age 65-69 years, 46 operations; $70-74$ years, 40 operations; $75-79$ years, 17 operations; and $\geq 80$ years, 23 operations. During 2015-2019, of 98 patients referred for meningioma, $67(68 \%)$ had surgery, 1 (1\%) had radiosurgery, and 31 $(32 \%)$ were observed. In the 11-year surgical cohort, comparing 173 patients $<65$ years versus 118 patients $\geq 65$ years old, there were no significant differences in tumor location, size, or outcomes. Of 126 cases of surgery in 118 elderly patients, the approach was a minimally invasive approach to skull base meningioma (SBM) in 64 cases (51\%) as follows: endonasal 18, supraorbital 28, minipterional 6, and retrosigmoid 12. Endoscope-assisted surgery was performed in $59.5 \%$ of patients. A conventional approach to SBM was performed in 15 cases (12\%) (endoscope-assisted $13.3 \%$ ), and convexity craniotomy for non-skull base meningioma (NSBM) in 47 cases (37\%) (endoscope-assisted 17\%). In these three cohorts (minimally invasive SBM, conventional SBM, and NSBM), the gross-total/near-total resection rates were $59.5 \%, 60 \%$, and $91.5 \%$, respectively, and an improved or stable Karnofsky Performance Status score occurred in $88.6 \%, 86.7 \%$, and $87.2 \%$ of cases, respectively. For these 118 elderly patients, the median LOS was 3 days, and major complications occurred in 10 patients (8\%) as follows: stroke $4 \%$, vision decline $3 \%$, systemic complications $0.7 \%$, and wound infection or death 0 . Eighty-three percent of patients were discharged home, and readmissions occurred in 5 patients (4\%). Meningioma recurrence occurred in 4 patients (3\%) and progression in $11(9 \%)$. Multivariate regression analysis showed no significance of American Society of Anesthesiologists physical status score, comorbidities, or age subgroups on outcomes; patients aged $\geq 80$ years showed a trend of longer hospitalization.

CONCLUSIONS This analysis suggests that elderly patients with meningiomas, when carefully selected, generally have excellent surgical outcomes and tumor control. When applied appropriately, use of minimally invasive approaches and endoscopy may be helpful in achieving maximal safe resection, reducing complications, and promoting short hospitalizations. Notably, one-third of our elderly meningioma patients referred for possible surgery from 2015 to 2019 were managed nonoperatively.

https://thejns.org/doi/abs/10.3171/2020.7.FOCUS20515

KEYWORDS meningioma; elderly; intracranial; tumor; endoscopic; keyhole

ABBREVIATIONS ASA = American Society of Anesthesiologists; EBL = estimated blood loss; GTR = gross-total resection; KPS = Karnofsky Performance Status; LOS = length of hospital stay; NTR = near-total resection; SRS = stereotactic radiosurgery; STR = subtotal resection.

SUBMITTED June 1, 2020. ACCEPTED July 21, 2020.

INCLUDE WHEN CITING DOI: 10.3171/2020.7.FOCUS20515. 
I NTRACRANIAL meningiomas are the most common primary brain tumor, and in most adult surgical series, almost half of meningioma patients are $\geq 65$ years old. ${ }^{1}$ Secondary to improved life expectancy and advances in neurodiagnostics, there appear to be increasing numbers of elderly patients with intracranial meningiomas who are surgical candidates. Prior studies have assessed major risk factors and surgical outcomes in elderly patients; however, there are limited reports of studies in which stratification of elderly patients by age was performed, and there is a paucity of reports assessing outcomes in elderly patients undergoing keyhole or minimally invasive surgical approaches. $^{2-6}$ We analyzed the surgical indications, risk factors, outcomes, complications, readmission rates, and tumor control in elderly patients ( $\geq 65$ years) undergoing a minimally invasive approach for the removal of skull base and non-skull base meningiomas. The primary goal of this study was to highlight surgical outcomes and the potential benefits and disadvantages of a minimally invasive strategy in elderly meningioma patients. As such, our outcomes are stratified separately for patients with skull base meningiomas undergoing a minimally invasive keyhole approach, those undergoing a conventional skull base approach, and patients with non-skull base meningiomas. ${ }^{7}$ To emphasize the importance of patient selection and management of incidentally discovered meningiomas, we also present a comparator cohort of patients referred to our clinic for meningioma who were managed without surgery. ${ }^{8,9}$

\section{Methods}

\section{Patient Population}

All patients who underwent surgical removal of an intracranial meningioma between January 2008 and August 2019 were identified. All operations were performed by neurosurgeons (D.F.K. or G.B.) at the Pacific Neuroscience Institute/John Wayne Cancer Institute, and all surgeries performed were neither overlapping nor concurrent. ${ }^{10} \mathrm{~A}$ retrospective analysis of a prospectively maintained database was done for consecutive meningioma patients from January 2008 to August 2019. This study was approved by the Institutional Review Board of the John Wayne Cancer Institute and Saint John's Providence Hospital, Santa Monica, California.

\section{Minimally Invasive Approach}

Since 2008, we have rarely utilized traditional open craniotomies for resection of skull base meningiomas at our institute. Instead, we have increasingly applied keyhole approaches, which we define as the use of a minimally invasive approach for a given tumor for which a conventional larger transcranial approach is often used instead. These keyhole approaches include 5 specific routes: the endoscopic endonasal route and 4 transcranial routes: supraorbital eyebrow, minipterional, and retromastoid approaches, and a gravity-assisted transfalcine approach. The specifics of these different approaches have been previously described by our group. ${ }^{11-17}$ For the endonasal route, in 2008-2009 endoscope assistance was used, but since 2010 a fully endoscopic approach has been used with a binostril two-surgeon approach performed by a neurosurgeon and otolaryngologist (ENT). ${ }^{16-18}$ For the keyhole craniotomies, no rigid brain retraction system was utilized. ${ }^{11,16,17,19}$

Patients with non-skull base convexity meningiomas and those with tentorial-based or falx-based meningiomas undergo a focused craniotomy with the bone flap following the smallest dimensions of the tumor, or a craniotomy that allows the most minimal amount of brain manipulation. In some instances, the ideal approach is a keyhole supraorbital or minipterional route to frontal and middle fossa meningiomas, or a gravity-assisted transfalcine approach to contralateral falx meningiomas (as we have previously described for brain metastases). ${ }^{11}$

\section{Outcome and Statistical Analysis}

Elderly patients were defined as $\geq 65$ years old per the definition used by the WHO. ${ }^{1}$ Preoperative American Society of Anesthesiologists (ASA) scores and comorbidities were noted for elderly patients undergoing removal of their intracranial meningioma. Patient demographic and tumor-related data were collected from the electronic medical record. Indications for surgery, including symptoms, tumor growth, mass effect, peritumoral edema, failed prior surgery, and/or radiation, were noted. Outcomes were dichotomized to short-term 90-day outcomes and long-term outcomes; 90-day outcomes primarily included all perioperative complications, return to the operating room, and readmissions. Surgical resection was categorized as follows: 1) gross-total resection (GTR), 2) near-total resection (NTR; $\geq 90 \%$ tumor resection with intentional residual tumor left over the neurovascular entity), or 3) subtotal resection (STR; < 90\% tumor resection). Simpson resection classification was not used, given that in this series of meningiomas, a majority of patients had meningiomas with extension invasion into the cavernous sinus, Meckel's cave, optic canal, orbit, infratemporal fossa, and/or paranasal sinuses, where complete resection of the involved bone and dura is typically not possible. Length of hospital stay (LOS) and discharge to home or rehabilitation were also recorded. To assess longterm outcomes, elderly patients undergoing surgery were analyzed for progression of residual tumor or recurrence and its management and functional outcome (Karnofsky Performance Status [KPS] score).

\section{Observational Cohort}

From 2015 onward (when our electronic medical record became operational), to detail the patients' demographic information and clinical and imaging presentation, we collected data on all elderly patients referred to our clinic for a presumed meningioma who were managed conservatively, without surgery. Using the same time frame (2015-2019) used for the operated cohort, we determined the proportion of operated versus nonoperated patients and compared their clinical characteristics.

\section{Statistical Analysis}

Statistical comparison of the means in the data among different groups was performed using ANOVA and Student t-tests. For LOS and comparing medians, we used nonpara- 
TABLE 1. Characteristics of 31 elderly patients with meningioma managed conservatively without surgery

\begin{tabular}{|c|c|c|c|c|c|c|c|}
\hline $\begin{array}{l}\text { Pt } \\
\text { No. }\end{array}$ & $\begin{array}{l}\text { Age, } \\
\text { Sex }\end{array}$ & $\begin{array}{l}\text { Tumor } \\
\text { Location }\end{array}$ & $\begin{array}{l}\text { Max Tumor } \\
\text { Diameter } \\
(\mathrm{mm})\end{array}$ & $\begin{array}{l}\text { Peritumoral } \\
\text { Edema }\end{array}$ & $\begin{array}{l}\text { Etiology } \\
\text { for Imaging }\end{array}$ & FU & $\begin{array}{l}\text { Latest } \\
\text { FU Status }\end{array}$ \\
\hline 1 & $73, \mathrm{~F}$ & Convexity & 30 & No & Headaches & $5 \mathrm{mos}$ & Asymptomatic, stable \\
\hline 2 & $74, \mathrm{~F}$ & Convexity & 33 & Yes & Incidental, metastasis WU & 12 mos & Asymptomatic, stable \\
\hline 3 & $76, F$ & Convexity & 12 & No & Dementia & 50 mos & Asymptomatic, stable \\
\hline 4 & $77, \mathrm{M}$ & Convexity & 16 & No & Incidental, trauma evaluation & $6 \mathrm{mos}$ & Asymptomatic, stable \\
\hline 5 & $80, F$ & Convexity & 54 & No & TIA & 60 mos & Asymptomatic, stable \\
\hline 6 & $81, \mathrm{M}$ & Convexity & 31 & Yes & Incidental, WU for IPH & $24 \mathrm{mos}$ & $\begin{array}{l}\text { Interval growth, patient chose } \\
\text { radiological FU }\end{array}$ \\
\hline 7 & $84, F$ & Convexity & 17 & No & Syncope & 52 mos & Asymptomatic, stable \\
\hline 8 & $85, \mathrm{M}$ & Convexity & 32 & No & Dementia & 32 mos & Asymptomatic, stable \\
\hline 9 & $85, F$ & Convexity & 30 & No & Headaches & $19 \mathrm{yrs}$ & Asymptomatic, stable \\
\hline 10 & $89, \mathrm{M}$ & Convexity & 20 & No & Dementia & No FU & \\
\hline 11 & $89, \mathrm{M}$ & Convexity & 11 & Yes & Incidental, trauma WU & 48 mos & Asymptomatic, stable \\
\hline 12 & $90, \mathrm{M}$ & Convexity & 38 & No & Dementia & No FU & \\
\hline 13 & $93, \mathrm{M}$ & Convexity & 12 & No & Ataxia & 43 mos & Asymptomatic, stable \\
\hline 14 & $67, \mathrm{~F}$ & CPA & 11 & No & Incidental, CIDP WU & $12 \mathrm{mos}$ & Asymptomatic, stable \\
\hline 15 & $80, F$ & CPA & 20 & No & Syncope & 120 mos & Asymptomatic, stable \\
\hline 16 & $69, \mathrm{~F}$ & CS & 14 & No & Intermittent diplopia & 14 mos & Stable, intermittent diplopia \\
\hline 17 & $86, \mathrm{~F}$ & Middle fossa & 17 & No & Incidental, metastasis WU & $24 \mathrm{mos}$ & Asymptomatic, stable \\
\hline 18 & $72, \mathrm{~F}$ & Middle fossa, CS & 38 & No & Incidental, no neurological symptoms & 84 mos & Asymptomatic, stable \\
\hline 19 & $75, \mathrm{~F}$ & Olfactory groove & 26 & No & Incidental, metastasis WU & 43 mos & Asymptomatic, stable \\
\hline 20 & $67, \mathrm{~F}$ & Parafalcine & 7 & No & Incidental, vetigo WU & $48 \mathrm{mos}$ & Asymptomatic, stable \\
\hline 21 & $70, F$ & Parafalcine & 12 & No & Incidental, no neurological symptoms & 12 mos & Asymptomatic, stable \\
\hline 22 & $74, \mathrm{~F}$ & Parafalcine & 26 & No & Incidental, no neurological symptoms & 120 mos & Stable, intermittent headaches \\
\hline 23 & $75, \mathrm{M}$ & Parafalcine & 28 & Yes & Incidental, no neurological symptoms & 144 mos & Asymptomatic, stable \\
\hline 24 & $85, \mathrm{~F}$ & Parafalcine & 12 & No & Vision loss WU & 4 mos & Asymptomatic, stable \\
\hline 25 & $87, \mathrm{~F}$ & Parafalcine & 43 & Yes & Incidental, no neurological symptoms & 13 yrs & Asymptomatic, stable \\
\hline 26 & $68, F$ & Tentorial & 15 & No & Incidental, vertigo WU & 3 mos & Asymptomatic, stable \\
\hline 27 & $69, \mathrm{~F}$ & Tentorial & 23 & No & Incidental, vertigo, syncope WU & $31 \mathrm{mos}$ & Asymptomatic, stable \\
\hline 28 & $74, \mathrm{~F}$ & Tentorial & 19 & No & Incidental, spine WU & 72 mos & Asymptomatic, stable \\
\hline 29 & $87, \mathrm{~F}$ & Tentorial & 21 & No & Incidental, dehydration WU & No FU & \\
\hline 30 & $74, \mathrm{~F}$ & Tuberculum sellae & 9 & No & Blurry vision & $12 \mathrm{mos}$ & Stable, blurry vision not from tumor \\
\hline 31 & $69, \mathrm{~F}$ & Tentorial & 28 & Yes & Incidental, hearing loss WU & 84 mos & $\begin{array}{c}\text { SRS for tumor growth, no growth } \\
\text { at } 18-\mathrm{mo} \text { FU }\end{array}$ \\
\hline
\end{tabular}

$\mathrm{CIPD}=$ chronic inflammatory demyelinating polyneuropathy; $\mathrm{CPA}=$ cerebellopontine angle; $\mathrm{CS}=$ cavernous sinus; $\mathrm{FU}=$ follow-up; IPH = intraparenchymal hemorrhage; $\mathrm{pt}=$ patient; $\mathrm{TI} \mathrm{A}=$ transient ischemic attack; $\mathrm{WU}=$ workup .

metric tests, including Kruskal-Wallis. Univariate analysis was done using chi-square studies, and if the number in one of the $2 \times 2$ grids was $>5$, we used Fisher's exact test. Binomial multivariate analysis was done using multivariate regression analysis, and $\mathrm{p}$ values $<0.05$ were considered statistically significant. Survival curves for testing binomial variables were plotted using Cox regression, and KaplanMeier survival curve graphs were plotted.

\section{Results}

\section{Elderly Patients Managed Conservatively}

From 2015 to 2019, of 97 patients seen in our clinic for presumed meningioma, $69 \%$ had surgery and $31 \%$ were observed. The 31 patients observed (Table 1) had a mean age of $78 \pm 8.2$ years, and tumor location was convexity in 13 patients, skull base in 7, parafalcine in 6 , and tentorial in 5 patients. The mean maximal tumor diameter was $22.5 \pm 11 \mathrm{~mm}$. In comparison, the patients undergoing surgery had a mean age of $72 \pm 6$ years and mean tumor diameter of $35 \pm 6 \mathrm{~mm}(\mathrm{p}=0.45)$. Follow-up data were available in 28 of 31 conservatively managed patients (range 3 months-19 years), and 26 of 28 patients were clinically stable with stable tumor diameter. One patient opted to continue monitoring despite tumor growth as he remained clinically stable. One patient opted for stereotactic radiosurgery (SRS; 2750 cGy over 5 fractions [550 cGy $\times 5])$ after substantial growth of her tentorial me- 
TABLE 2. Comparison of nonelderly and elderly patients undergoing surgery for meningioma

\begin{tabular}{|c|c|c|c|}
\hline & \multicolumn{2}{|c|}{ Cases ( $n=323$ ops in 291 pts) } & \multirow[b]{2}{*}{ p Value } \\
\hline & Nonelderly ( $n=197$ ops in 173 pts) & Elderly ( $n=126$ ops in 118 pts) & \\
\hline Age, yrs & $<65$ & $\geq 65$ & \\
\hline Preop KPS score $>70$ & $165(83.8)$ & $92(73)$ & 0.02 \\
\hline Skull base & $134(68)$ & $79(62.7)$ & 0.32 \\
\hline Mean max tumor diameter, $\mathrm{mm}$ & 33 & 35 & 0.22 \\
\hline Invasion to Meckel's cave/CS/orbit/infratemporal fossa & $51(26)$ & $29(23)$ & 0.56 \\
\hline Tumor w/ vascular encasement & $116(59)$ & $71(56.3)$ & 0.65 \\
\hline Redo op & $48(24.4)$ & $25(20)$ & 0.10 \\
\hline Prior radiation & $32(16.2)$ & $11(8.7)$ & 0.053 \\
\hline Keyhole approach, total & $132(67)$ & $70(55.5)$ & 0.40 \\
\hline Endoscopic endonasal & $51(38.5)$ & $18(25.7)$ & \\
\hline Supraorbital & $34(25.7)$ & $32(45.7)$ & \\
\hline Minipterional & $11(8.3)$ & $7(10)$ & \\
\hline Retromastoid & $33(25)$ & $12(17.2)$ & \\
\hline Transfalcine & $3(0.5)$ & $1(1.4)$ & \\
\hline Endoscope use during op & $98(49.7)$ & $55(43.6)$ & 0.42 \\
\hline GTR/NTR & $132(67)$ & $90(71.4)$ & 0.40 \\
\hline Mean EBL, ml & $332 \pm 374$ & $216 \pm 326$ & 0.7 \\
\hline Mean op duration, mins & $337 \pm 166$ & $295.1 \pm 138$ & 0.01 \\
\hline Median LOS, days & $3(1-27)$ & $3(1-20)$ & 0.55 \\
\hline LOS $>5$ days & $15(7.6)$ & $16(12.7)$ & 0.13 \\
\hline Good functional outcome (improved/stable postop KPS score) & $164(83.2)$ & $112(88.2)$ & 0.22 \\
\hline Major complication & $16(8)$ & $11(8.7)$ & 0.62 \\
\hline Readmission w/in 90 days & $11(5.6)$ & $5(4)$ & 0.51 \\
\hline
\end{tabular}

Values are presented as number of operations (\%), median (range), or mean $\pm \mathrm{SD}$, unless otherwise indicated.

ningioma over several years. Subsequently, at the time of this report, her tumor has remained stable for 18 months following SRS.

\section{Demographic and Preoperative Clinical Factors}

The surgical cohort operated on between 2008 and 2019 included 291 patients (median age 60 years [range 24-93 years], $71.5 \%$ females, mean follow-up 36 months) who underwent 323 operations (23\% redo, skull base, 213/323, $66 \%$ ). Of these 323 operations, 126 (39\%) were performed in 118 elderly patients (age 65-69 years, 46 operations; 70-74 years, 40 operations; 75-79 years, 17 operations; and $\geq 80$ years, 23 operations). Of these operations, 25 of $126(20 \%)$ were redo operations; 79 (63\%) were for skull base meningiomas, and 47 (37\%) were for non-skull base meningiomas. The number of patients with preoperative KPS score $\geq 70$ was higher in the nonelderly cohort (165 [83.8\%] vs 92 [73\%], $\mathrm{p}=0.02$ ). There were no significant differences in tumor location, maximum tumor diameter, invasiveness to Meckel's cave/cavernous sinus/orbit/infratemporal fossa, and vascular encasement between the two groups (Table 2). In the elderly group, 92 cases (73\%) had an ASA score of $\geq 3$. Tumor pathology was WHO grade I in 106 tumors (84\%), WHO grade II in 19 tumors (15\%), and WHO grade III in 1 tumor (1\%).
Indications for Surgical Management in the Elderly Cohort

Surgical indications for the elderly patients with meningiomas are stratified in Table 3. The most common indication for surgery in our series was tumor-related neurological symptoms with or without peritumoral edema $(67 / 126$, $53.2 \%$ ). Among the patients undergoing surgery, 8 patients presented with their meningioma as an incidental finding. Of these 8 patients, peritumoral edema was noted in 4 patients; the mean maximal tumor diameter in the 4 patients without edema was $25 \pm 15 \mathrm{~mm}$.

\section{Tumor Description, Intraoperative Characteristics, Complications, and Functional Outcomes in the Elderly Population}

Skull Base Meningiomas: Minimally Invasive Approach

Of the total 126 operations performed in 118 patients, surgery for skull base meningioma was performed in 79 cases (63\%) and, of these, 14 cases $(17.7 \%)$ were redo operations and 5 of the patients had had previous radiation treatment. A minimally invasive approach was used in 64 skull base operations (81\%) (endonasal 18, supraorbital 28 , minipterional 6 , retrosigmoid 12 ), and a conventional skull base approach was used in $15(19 \%)$ (middle fossa 5 , pterional 10). For the 64 operations with a minimally invasive approach, $50(63.3 \%)$ were in patients with an ASA score $\geq 3$, and $\geq 3$ comorbidities were present in 39 of 
TABLE 3. Indications for surgical intervention in elderly meningioma patients

\begin{tabular}{lc}
\hline \multicolumn{1}{c}{ Indications for Surgery } & $\begin{array}{c}\text { No. of } \\
\text { Cases (\%) }\end{array}$ \\
\hline Clinical symptoms & $34(27)$ \\
\hline Peritumoral edema and clinical symptoms & $33(26.2)$ \\
\hline Tumor growth, peritumoral edema, clinical symptoms & $13(10.3)$ \\
\hline Tumor growth & $12(9.5)$ \\
\hline Tumor growth, clinical symptoms & $10(7.9)$ \\
\hline Symptomatic recurrence & $8(6.3)$ \\
\hline Tumor growth, peritumoral edema & $7(5.6)$ \\
\hline Incidental, peritumoral edema & $4(3.2)$ \\
\hline Incidental, patient preference & $4(3.2)$ \\
\hline Staged surgery & $1(0.8)$ \\
\hline Total & 126 \\
\hline
\end{tabular}

these 64 patients (61\%). The mean maximal tumor diameter was $31 \pm 13 \mathrm{~mm}$; tumors with a maximum diameter of $>3 \mathrm{~cm}$ were seen in 29 cases $(45 \%)$, and invasiveness to Meckel's cave/cavernous sinus/orbit/infratemporal fossa was seen in 28 of the 79 skull base meningioma cases (35.4\%). In these 79 cases, GTR was achieved in 33 cases $(41.8 \%)$ and GTR/NTR combined was achieved in 47 cases $(59.5 \%)$. Of the 64 cases in which a minimally invasive approach was used for skull base meningiomas, $40(62.5 \%)$ had one of the following resectability-limiting features: 1) invasiveness to Meckel's cave/cavernous sinus/orbit/infratemporal fossa, 2) redo operation, or 3) lack of an arachnoid plane and adherence to neurovascular structures. The GTR/NTR rates in patients with these limiting factors in comparison to the rates in patients lacking these risk factors were 35\% (14/40) versus $100 \%$ $(24 / 24)(\mathrm{p}<0.001)$.

Apart from the 18 patients with skull base meningiomas who underwent an endoscopic endonasal approach, endoscopy was utilized in 29 of the 47 nonendonasal skull base cases (62\%). Endoscopy was deemed helpful in achieving additional tumor removal in 12 patients $(41.4 \%)$. Of the 29 craniotomy cases for which an endoscope was useful for additional removal, in 5 of 12 cases (41.7\%) NTR was converted to GTR with the use of endoscopy.

The mean duration of surgery for the overall cohort was $326 \pm 137$ minutes, the mean estimated blood loss (EBL) was $291.5 \pm 287 \mathrm{ml}$, and the mean and median LOS were 3.7 and 3 days. LOS $>5$ days in the young versus elderly cohort occurred in $7.6 \%$ versus $12.7 \%$ of patients, respectively $(\mathrm{p}=0.13)$. Major complications occurred in 8 of 64 cases (12.5\%) and are detailed in Table 4. There was 1 readmission within 90 days for a chronic subdural hematoma that was managed conservatively. Improved or stable KPS scores were seen in 57 of 64 cases (89.1\%) at the latest follow-up.

\section{Skull Base Meningiomas: Conventional Approach}

Of 15 patients who underwent a conventional surgical approach (middle fossa 5, pterional 10), 11 patients (73\%) had an ASA score of $\geq 3$, and 8 patients (53.3\%) had $\geq 3$
TABLE 4. Neurological complications, systemic complications, and readmissions

\begin{tabular}{ll}
\hline \multicolumn{1}{c}{ Complication } & No. of Pts \\
\hline Major neurological $(\mathrm{n}=10,7.9 \%)^{*}$ & 5 \\
\hline Stroke & 2 \\
\hline Hematoma & 4 \\
\hline Worsening vision & 0 \\
\hline Wound infection & 0 \\
\hline Meningitis & 0 \\
\hline CSF leak & 1 \\
\hline Major systemic complications $(\mathrm{n}=1,0.8 \%)$ & 0 \\
\hline Aspiration pneumonia & 2 \\
\hline DVT/PE/cardiac event & 1 \\
\hline Readmissions ( $\mathrm{n}=5,4 \%)$ & 1 \\
\hline SDH (managed conservatively) & 1 \\
\hline Worsening brain edema & \\
\hline Seroma & \\
\hline Transient neurological decline & \\
\hline
\end{tabular}

DVT = deep vein thrombosis; $\mathrm{PE}=$ pulmonary embolism; $\mathrm{SDH}=$ subdural hematoma.

* One patient had both postoperative hematoma and stroke.

comorbidities. The mean maximum tumor diameter was $37 \mathrm{~mm}$. GTR was achieved in 7 of 15 patients (46.6\%) and GTR/NTR was achieved in 9 of 15 patients (60\%). GTR/ NTR rates in patients with limiting factors (as mentioned above) in comparison with the rates in patients without these risk factors were 45.5\% (5/11) versus 100\% (4/4) $(\mathrm{p}=$ 0.05 ). Endoscope assistance was used in 2 patients and was helpful in removing additional tumor in 1 patient. The mean duration of surgery was $239 \pm 79$ minutes. The mean EBL was $367 \pm 362 \mathrm{ml}$, and the mean and median LOS were 4.8 and 4 days, respectively. Major complications were seen in 2 cases (13\%), including 1 hospital readmission within 90 days for a chronic subdural hematoma that was managed conservatively. An improved or stable KPS score was seen in 13 patients $(86.7 \%)$ at the latest follow-up.

\section{Non-Skull Base Meningiomas}

Of the total 47 operations in 43 patients for non-skull base (predominantly convexity) meningiomas, 7 cases (15\%) were redo operations, of which 4 cases had been treated with prior radiation, and ASA scores $\geq 3$ were found in 42 cases (89\%) and $\geq 3$ comorbidities in 23 cases (48.9\%). The mean maximum tumor diameter was $42 \mathrm{~mm}$. Of the 47 non-skull base operations, $6(13 \%)$ were performed via keyhole approaches. Of the 41 conventional nonkeyhole skull base approaches, GTR was achieved in 28 of 41 cases $(68.2 \%)$ and GTR/NTR was achieved in 37 of 41 cases $(90.2 \%)$. Endoscopy was used in 8 of 47 cases $(17 \%)$ (a supraorbital approach for anterior frontobasal meningioma in 4 cases, frontal craniotomy for parafalcine meningioma in 2 cases, minipterional for frontal convexity meningioma in 1 case, and gravity-assisted transfalcine for parafalcine meningioma in 1 case). Use of the endoscope allowed for additional tumor removal in 
TABLE 5. Elderly meningioma patient characteristics and surgical outcomes, stratified by age group

\begin{tabular}{|c|c|c|c|c|c|}
\hline & \multicolumn{4}{|c|}{ Age Group, Yrs } & \multirow{2}{*}{$\begin{array}{c}p \\
\text { value }\end{array}$} \\
\hline & $65-69$ & $70-74$ & $75-79$ & $\geq 80$ & \\
\hline $\begin{array}{l}\text { Total no. of ops } \\
(n=126)\end{array}$ & 46 & 40 & 17 & 23 & \\
\hline $\begin{array}{l}\text { ASA score } \\
\geq 3 \text { ( } n=92)\end{array}$ & $28(61)$ & $30(75)$ & $15(88.2)$ & $19(82.6)$ & 0.08 \\
\hline$\geq 3$ comorbidities & $18(39)$ & $15(37.5)$ & $11(64.7)$ & $18(78.3)$ & 0.004 \\
\hline $\begin{array}{l}\text { KPS score } \\
\text { stable/improved }\end{array}$ & $42(91.3)$ & $33(82.5)$ & $15(88.2)$ & $21(91.3)$ & 0.59 \\
\hline Redo op $(n=21)$ & $5(11)$ & $8(20)$ & $3(17.6)$ & $5(21.7)$ & 0.60 \\
\hline $\begin{array}{l}\text { Skull base tumor } \\
(n=79)\end{array}$ & $28(61)$ & $27(67.5)$ & $10(58.8)$ & $14(61)$ & 0.89 \\
\hline GTR/NTR & $35(76)$ & $28(70)$ & $13(76.5)$ & $14(61)$ & 0.57 \\
\hline $\begin{array}{l}\text { Max tumor } \\
\text { diameter, } \mathrm{mm}\end{array}$ & 32 & 34.6 & 35.7 & 41.8 & 0.12 \\
\hline Mean EBL, ml & 287 & 310 & 207 & 455 & 0.19 \\
\hline $\begin{array}{l}\text { Mean op duration, } \\
\text { mins }\end{array}$ & 296 & 296 & 300 & 286 & 0.99 \\
\hline Mean LOS, days* & 3.4 & 3.4 & 3.3 & 3.9 & 0.88 \\
\hline
\end{tabular}

7 of 8 cases (87.5\%), and in 6 of 7 cases (86\%) NTR was converted to GTR with endoscopy. The mean duration of surgery was $237 \pm 121$ minutes, the mean EBL was $354 \pm$ $488 \mathrm{ml}$, and the mean and median LOS were both 3 days. Major complications occurred in 5 of the 47 cases (11\%), and there were 3 readmissions within 90 days. Improved or stable KPS scores were seen in 41 cases $(87.2 \%)$ at the latest follow-up.

\section{LOS and Complications}

In the overall cohort of 118 elderly patients, LOS $>5$ days, which occurred in 16 cases (12.7\%), did not significantly differ in patients with an ASA score of $\geq 3$ or more, more comorbidities $(\geq 3)$, higher preoperative KPS score $(>70)$, good functional outcome, history of prior radiation or surgery, larger tumor diameter $(\geq 3 \mathrm{~cm})$, or GTR versus NTR resection. However, among the elderly patients ( $\geq 65$ years old) the analysis showed longer LOS in patients aged $\geq 80(12 / 39,30.8 \%)$ or $70-74(12 / 39,30.8 \%)$ years than in patients aged $65-69(9 / 39,23.1 \%)$ or $75-$ $79(6 / 39,15.4 \%)$ years. Multivariate regression analysis, when controlled for ASA score and comorbidities, did not show significant differences within the groups but showed a trend of longer LOS in the group of patients aged $\geq 80$ years. Similarly, multivariate analysis showed no statistically significant association of ASA score or comorbidities with achievement of a good functional outcome in the elderly subgroups.

Overall, major neurological complications were seen in 10 of the patients (7.9\%), a major systemic complication in 1 patient, and readmission in 5 patients (Table 4). Of the 5 patients who had strokes, none were neurologically devastated, all had improvement of symptoms and maintained good quality of life at last follow-up, and none of them had a KPS score decline to $<80$.

A subgroup analysis among the elderly population revealed no significant differences in any of the patient/ tumor/intraoperative/functional outcome features, except that the $\geq 80$-year age group had a higher number of comorbidities (Table 5). In total, $83.4 \%$ of patients were discharged home, while $16.6 \%$ went to a short-term rehabilitation center/skilled nursing facility. Table 6 highlights the resection rates, complications, and LOS for different surgical approaches and compares the minimally invasive approaches with the conventional approaches. Notably, no endonasal approaches resulted in GTR, because in

TABLE 6. Meningioma resection rates, complication rates, and LOS by minimally invasive and conventional surgical approaches

\begin{tabular}{|c|c|c|c|c|c|c|}
\hline & $\begin{array}{l}\text { Endonasal } \\
\qquad(\mathrm{n}=18)^{*}\end{array}$ & $\begin{array}{l}\text { Supraorbital } \\
\qquad(n=32)\end{array}$ & $\begin{array}{l}\text { Minipterional } \\
\quad(n=7)\end{array}$ & $\begin{array}{l}\text { Retrosigmoid/Suboccipital } \\
\qquad(n=12)\end{array}$ & $\begin{array}{l}\text { Transfalcine } \\
\quad(n=1)\end{array}$ & p Value \\
\hline GTR & $0(0)$ & $17(53)$ & $5(71.4)$ & $9(75)$ & $0(0)$ & $<0.001$ \\
\hline GTR/NTR & $1(5.6)$ & $25(78)$ & $6(85.7)$ & $11(91.7)$ & $1(100)$ & $<0.001$ \\
\hline Complications & $1(5.6)$ & $6(18.8)$ & $1(14.3)$ & $0(0)$ & $0(0)$ & 0.34 \\
\hline Median LOS, days & 2 & 3 & 2 & 2 & 3 & 0.16 \\
\hline \multirow[t]{2}{*}{ LOS >5 days } & $4(22.2)$ & $4(12.5)$ & $0(0)$ & $1(8.3)$ & $0(0)$ & 0.53 \\
\hline & $\begin{array}{l}\text { Pterional Skull Base } \\
\qquad(\mathrm{n}=10)\end{array}$ & $\begin{array}{l}\text { Middle Fossa Skull } \\
\text { Base }(n=5)\end{array}$ & $\begin{array}{l}\text { Pterional Non-Skull } \\
\text { Base }(n=3)\end{array}$ & $\begin{array}{c}\text { Convexity/Parafalcine } \\
(n=38)\end{array}$ & - & $\mathrm{p}$ Value \\
\hline GTR & $4(40)$ & $3(71.4)$ & $3(100)$ & $25(65.8)$ & - & $<0.001$ \\
\hline GTR/NTR & $5(50)$ & $4(80)$ & $3(100)$ & $34(89.5)$ & - & $<0.001$ \\
\hline Complications & $1(10)$ & $0(0)$ & $0(0)$ & $1(2.6)$ & - & 0.34 \\
\hline Median LOS, days & 4 & 2 & 2 & 2.5 & - & 0.16 \\
\hline LOS $>5$ days & $3(30)$ & $1(20)$ & $0(0)$ & $3(8)$ & - & 0.53 \\
\hline
\end{tabular}

Values are presented as number of cases (\%) unless otherwise indicated.

* Sixteen of 18 cases had extensive cavernous sinus/Meckel's cave invasion, and surgical goals in these patients were tumor debulking and bony decompression; 2 of 18 cases had dense adhesions to neurovascular structures. 
TABLE 7. Meningioma recurrence and progression for different patient cohorts and clinical variables

\begin{tabular}{|c|c|c|}
\hline & Recurrence/Progression $(n=15)$ & $\mathrm{p}$ Value \\
\hline Age, yrs & & 0.03 \\
\hline $65-69$ & $2(1.7)$ & \\
\hline $70-74$ & $6(5.1)$ & \\
\hline $75-79$ & $1(0.8)$ & \\
\hline$\geq 80$ & $6(5.1)$ & \\
\hline Redo cases & $4(3.4)$ & 0.14 \\
\hline First op cases & $11(9.3)$ & \\
\hline Skull base & $11(9.3)$ & 0.2 \\
\hline Non-skull base & $4(3.4)$ & \\
\hline GTR & $4(3.4)$ & 0.03 \\
\hline Non-GTR & $11(9.3)$ & \\
\hline GTR/NTR & $9(7.6)$ & 0.2 \\
\hline STR & $6(5.1)$ & \\
\hline
\end{tabular}

Values are presented as number of cases (\%).

16 of 18 cases the patients had extensive cavernous sinus or Meckel's cave invasion and the goals of surgery were tumor debulking and bony decompression, and the $2 \mathrm{ad}-$ ditional patients had dense neurovascular adhesions precluding GTR.

\section{Tumor Control}

Of the 118 elderly patients, follow-up of $\geq 3$ months was available in 102 patients (mean 35.3 months, range 3-126 months). Of these 102 patients, recurrence was seen in 4 patients $(3.9 \%)$ and progression of residual tumor was noted in 11 patients $(10.8 \%)$. Of these 15 patients, pathology was grade I in 11 patients (73.3\%) and grade II in 4 patients (26.7\%). The mean time to recurrence was 19 months and to progression was 28 months. Univariate analysis showed that the 70- to 74-year and $\geq 80$-year age groups had relatively higher recurrence/progression rates than the other age groups (Table 7). The mean times to progression or recurrence for different elderly cohorts were +18 months for the 65- to 69-year age group; 28 months for the 70- to 74year age group; 5 months for the 75- to 79-year age group; and 17.3 months for the $\geq 80$-year age group. Further associations of tumor control with redo surgery, skull base location, and GTR are depicted in Kaplan-Meier curves (Fig. 1).

Multivariate regression analysis, when controlled for the above clinical factors, including ASA score and comorbidities, did not reveal statistical significance in recurrence or progression rates between the elderly patient groups. Of the 15 patients with recurrence/progression, 8 were managed with stereotactic radiation therapy, 2 with medical management (chemotherapy), 2 with repeat surgery, and 1 with a combination of radiotherapy and surgery. Of these 15 patients, 3 patients had another recurrence, which required further treatment with surgery, surgery + stereotactic radiotherapy, and chemotherapy, respectively (Supplemental Table 1).

\section{Discussion}

\section{Decision for Surgery and Preoperative Evaluation}

Intracranial meningiomas are the most common primary brain tumors, as recognized by the CBTRUS (Central Brain Tumor Registry of the United States), whose recent report showed that $49 \%$ of meningioma patients were $\geq 65$ years old. ${ }^{1}$ Considering that most meningiomas are benign (typical) and have the highest incidence, neurosurgeons frequently encounter these patients in their practices. Numerous prior articles have questioned whether elderly patients should be offered surgery and what the key criteria are for surgery, radiation/radiosurgery versus conservative management. ${ }^{5,18-22}$ As shown in this cohort, we propose that similar to younger patients, elderly patients with symptomatic meningiomas, those with significant mass effects with or without peritumoral edema, and those with MRI-documented tumor progression are reasonable candidates for surgery. ${ }^{25}$ However, surgery is clearly not warranted in all patients with meningiomas, and many patients $>65$ years can be observed, which was the case in our cohort from 2015 to 2019, when almost a third of patients we saw in our clinic were counseled against surgery and instead recommended watchful waiting with serial MRI studies. ${ }^{8,9}$

Notably, some symptomatic elderly patients who have significant preexisting conditions, who are at a higher risk of general anesthesia, and/or who have primary cavernous sinus meningiomas or smaller growing meningiomas can potentially be managed safely with stereotactic radiother-

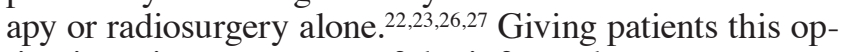
tion is an important part of the informed consent process and was the treatment opted for by 1 patient with an incidental but growing posterior fossa convexity/tentorial meningioma, who was doing well at the time of this report, 18 months after SRS, and was without further tumor growth.

\section{Preoperative and Anesthesia Considerations}

All of our patients undergo thorough medical clearance and further subspecialty clearance as recommended by the medicine physician, clearance that is further evaluated by our neuro-anesthesia team before surgery. Any systemic concerns or patients with ASA scores of 4 are extensively discussed in a multidisciplinary fashion, and then we proceed with surgery once the patient's safety is established. The type of general anesthesia, especially in elderly patients, likely plays an important role in the recovery process. Our neuro-anesthesia team uses propofol-based total intravenous anesthesia as it has been shown to decrease the risk of postoperative cognitive dysfunction. ${ }^{28}$

\section{Do Patients Benefit From a Minimally Invasive Approach?}

Ekşi et al. recently published an extensive review of literature on complications encountered during surgery of elderly patients with intracranial meningiomas. ${ }^{29}$ The review reported an overall postsurgical complication rate in elderly patients of $33.64 \%$. Further, studies that reported neurological and systemic complications separately demonstrated $18.3 \%$ and $16.4 \%$ complication rates, respectively. ${ }^{29}$ Thirty-day mortality was $4.3 \%$ (range $0 \%-55 \%$ ). In addition to the reported outcomes, we reviewed the in- 

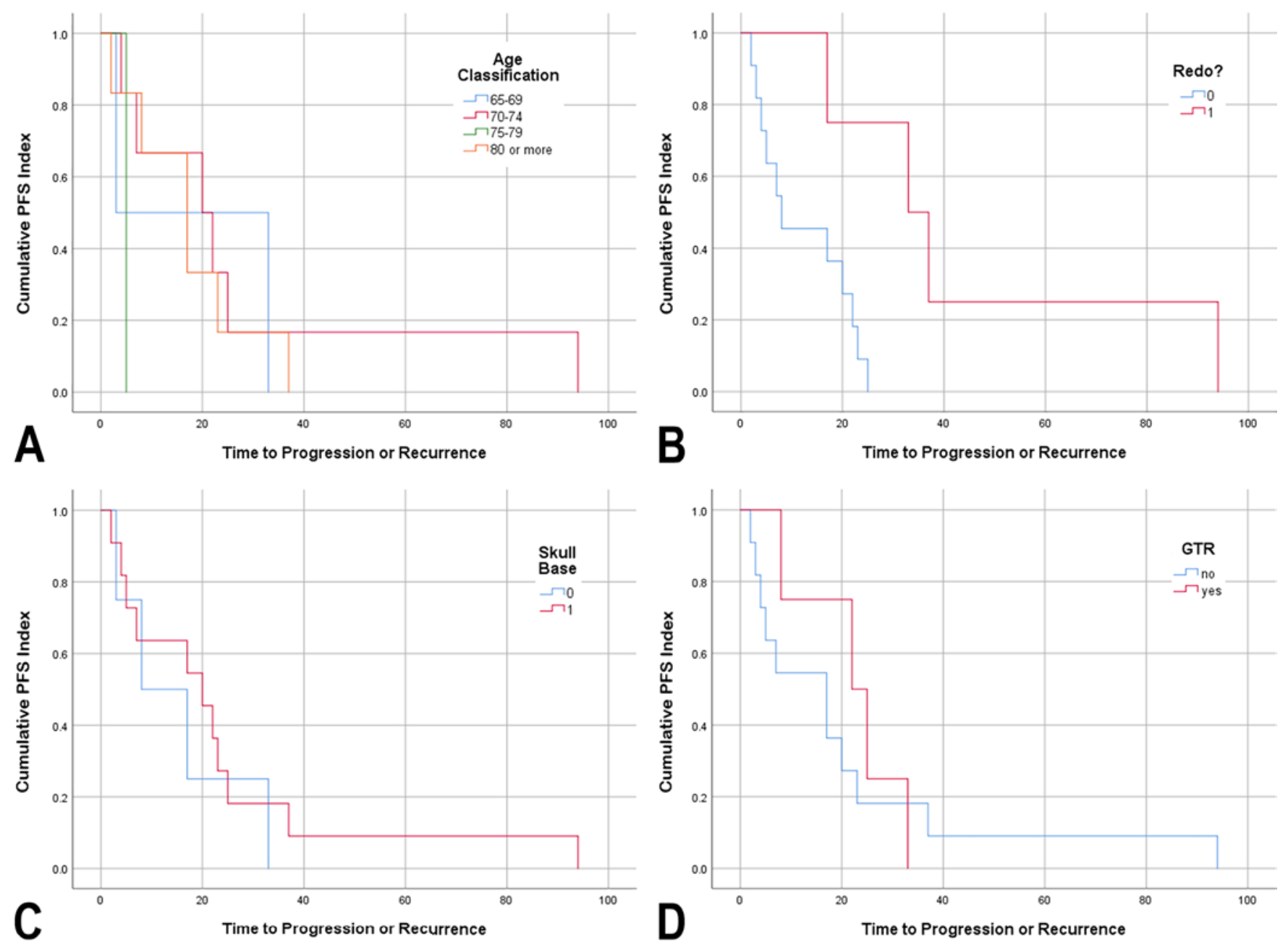

FIG. 1. Mean times to progression or recurrence in the elderly patient cohort. A: By age: $65-69$ years, 18 months; $70-74$ years, 28 months; $75-79$ years, 5 months; and $\geq 80$ years, 17.3 months. B: First-time cases, 12.3 months; redo cases, 45.2 months $(p=0.01)$. C: Skull base meningiomas, 15 months; non-skull base meningiomas, 23 months. D: GTR cases, 22 months; non-GTR cases, 20.8 months. PFS = progression-free survival.

cluded studies by Ekşi et al. and noted that the mean LOS was reported in 9 studies ${ }^{5,20,30-36}$ and ranged between 4 and 25.7 days, with a mean LOS of 14.3 days. Of the 9 studies that reported LOS, 8 studies $(89 \%)$ had a mean LOS $>5$ days. Our mean and median LOS were 3.7 and 3 days, respectively, for the minimally invasive skull base approach cohort, and only $12.7 \%$ of our patients had an LOS > 5 days. A small proportion of our patients required narcotics at discharge, and no patients were prescribed narcotics beyond postoperative days (PODs) 10-14.

In our study, good functional outcomes (stable or improved KPS scores) were seen in $88 \%$ of cases. Neurological complications were seen in 12 cases (10\%), a systemic complication (aspiration pneumonia) was seen in 1 patient $(0.8 \%)$, and readmissions occurred in 5 cases $(4 \%)$. No prior study to our knowledge has reported readmission rates in an elderly patient population undergoing meningioma resection. Our 90-day mortality rate was $0 \%$. Notably, we counsel our patients and their families prior to surgery that they will likely be able to leave the hospital by POD
2, mentally preparing them for a relatively short hospital stay; $83.4 \%$ of our patients were discharged to home in this series.

Steinberger et al. evaluated the American College of Surgeons National Surgical Quality Improvement Program database to determine the safety of meningioma resection in 1568 patients. ${ }^{24}$ These investigators found that octogenarians had a 30-day mortality rate of $8.6 \%$ and an overall complication rate of $31.2 \%$. Compared with younger patients, octogenarians had a 16-fold increase in the odds of death within 30 days, a 2-fold increase in the odds of experiencing any complication, and a 3 -fold increase in prolonged LOS. In the present study, overall outcomes, complication rates, and LOS in patients $>80$ years were similar to those in other elderly populations.

\section{Surgical Philosophy for Meningiomas}

The use of minimally invasive approaches for intracranial meningiomas is based in a philosophy and practice of minimal brain exposure and manipulation that includes 
working through smaller corridors without static brain retractors and augmenting visualization by endoscopic views when needed, with the ultimate goal of achieving maximal safe tumor removal. ${ }^{12-14,16,17,19,37}$ In our experience, for both young and old patients, use of smaller incisions, more focused craniotomies, and less expansive brain exposure not only promotes a greater likelihood of operative site healing and excellent cosmesis, but also is associated with less postoperative pain and a greater willingness by patients to mobilize and leave the hospital. Given that meningiomas are predominantly benign, radiosensitive tumors, we feel that the key goals of surgery, especially in older patients, should be maximal safe removal, restoration of quality of life, and avoidance of complications. The aggregate results presented here in terms of extent of resection, complications, and LOS would appear to support this approach. Prior studies and our current experience demonstrate a surgical reality, that complication rates and LOS are inextricably linked; simply put, complications beget longer, more intensive hospitalizations and reoperations, especially in older patients. ${ }^{29,36,38-40}$

Regarding extent of resection, our reported GTR and NTR rates for skull base and non-skull base meningiomas, as well as long-term tumor control rates (albeit with short follow-up), are similar to those reported for many prior series..$^{3,29,36,38-40}$ However, our rates of poor functional outcomes, surgical complications, and LOS are considerably lower than those of most prior series of elderly meningioma patients. . $^{3,29,36} \mathrm{We}$ attribute these quantitative and qualitative differences at least in part to the use of minimally invasive keyhole surgical approaches in the current study. In total, of all the approaches performed, 70 of 126 total operations $(56 \%)$ were minimally invasive/keyhole and $55(78.5 \%)$ included the use of endoscopy, which aided in additional tumor removal in 37 cases $(67 \%)$.

\section{Study Limitations}

There is an overall study sample bias inherent to the retrospective nature of the study; however, prospective data collection was intended to lower this bias. Additionally, our philosophy, while primarily managing symptomatic meningiomas, is to favor surgical resection over the use of radiosurgery; hence, there is a selection bias for surgery. Overall, the cohort had a median 3-year follow-up, which is relatively short for patients with predominantly grade I meningiomas.

\section{Conclusions}

Approximately one-third of elderly patients seen for a presumed meningioma in our neurosurgical clinical practice over a 5-year period were managed with observation. Over the entire 11-year study period, for those elderly patients with symptomatic or growing meningiomas whose tumors did warrant surgery, our results indicate that excellent overall outcomes can be achieved with low risks of morbidity and mortality. Utilization of minimally invasive intracranial approaches with reasonable surgical goals may help improve clinical and functional outcomes and promote a shorter LOS after surgical treatment of meningioma in elderly patients.

\section{Acknowledgments}

The authors would like to acknowledge the Pacific Neuroscience Institute Foundation and Saint John's Health Center Foundation for their support.

\section{References}

1. Achey RL, Gittleman H, Schroer J, et al. Nonmalignant and malignant meningioma incidence and survival in the elderly, 2005-2015, using the Central Brain Tumor Registry of the United States. Neuro Oncol. 2019;21(3):380-391.

2. Brokinkel B, Holling M, Spille DC, et al. Surgery for meningioma in the elderly and long-term survival: comparison with an age- and sex-matched general population and with younger patients. J Neurosurg. 2017;126(4):12011211.

3. Ikawa F, Kinoshita Y, Takeda M, et al. Review of current evidence regarding surgery in elderly patients with meningioma. Neurol Med Chir (Tokyo). 2017;57(10):521-533.

4. Poon MT-C, Fung LH-K, Pu JK-S, Leung GK-K. Outcome comparison between younger and older patients undergoing intracranial meningioma resections. J Neurooncol. 2013; 114(2):219-227.

5. Poon MT-C, Fung LH-K, Pu JK-S, Leung GK-K. Outcome of elderly patients undergoing intracranial meningioma resection-a systematic review and meta-analysis. Br J Neurosurg. 2014;28(3):303-309.

6. Zhao X, Zhao D, Wu Y, et al. Meningioma in the elderly: characteristics, prognostic factors, and surgical strategy. $J$ Clin Neurosci. 2018;56:143-149.

7. Savardekar AR, Patra DP, Bir S, et al. Differential tumor progression patterns in skull base versus non-skull base meningiomas: a critical analysis from a long-term follow-up study and review of literature. World Neurosurg. 2018;112:e74-e83.

8. Oya S, Kim S-H, Sade B, Lee JH. The natural history of intracranial meningiomas. J Neurosurg. 2011;114(5):12501256.

9. Chamoun R, Krisht KM, Couldwell WT. Incidental meningiomas. Neurosurg Focus. 2011;31(6):E19.

10. Self DM, Ilyas A, Stetler WR. Safety of running two rooms: a systematic review and meta-analysis of overlapping neurosurgical procedures. World Neurosurg. 2018;116:e179-e186.

11. Barkhoudarian G, Farahmand D, Louis RG, et al. Microsurgical endoscope-assisted gravity-aided transfalcine approach for contralateral metastatic deep medial cortical tumors. Oper Neurosurg (Hagerstown). 2017;13(6):724-731.

12. Cook SW, Smith Z, Kelly DF. Endonasal transsphenoidal removal of tuberculum sellae meningiomas: technical note. Neurosurgery. 2004;55(1):239-246.

13. Ditzel Filho LFS, McLaughlin N, Bresson D, et al. Supraorbital eyebrow craniotomy for removal of intraaxial frontal brain tumors: a technical note. World Neurosurg. 2014;81(2): 348-356.

14. Dusick JR, Esposito F, Kelly DF, et al. The extended direct endonasal transsphenoidal approach for nonadenomatous suprasellar tumors. J Neurosurg. 2005;102(5):832-841.

15. Fatemi N, Dusick JR, de Paiva Neto MA, Kelly DF. The endonasal microscopic approach for pituitary adenomas and other parasellar tumors: a 10-year experience. Neurosurgery. 2008;63(4)(suppl 2):244-256.

16. Kelly DF, Griffiths CF, Takasumi Y, et al. Role of endoscopic skull base and keyhole surgery for pituitary and parasellar tumors impacting vision. J Neuroophthalmol. 2015;35(4): 335-341.

17. Sivakumar W, Barkhoudarian G, Lobo BM, et al. Strategy and technique of endonasal endoscopic bony decompression and selective tumor removal in symptomatic skull base meningiomas of the cavernous sinus and Meckel's cave. World Neurosurg. 2019;131:e12-e22. 
18. Conger A, Zhao F, Wang X, et al. Evolution of the graded repair of CSF leaks and skull base defects in endonasal endoscopic tumor surgery: trends in repair failure and meningitis rates in 509 patients. J Neurosurg. 2018;130(3):861-875.

19. Wilson DA, Duong H, Teo C, Kelly DF. The supraorbital endoscopic approach for tumors. World Neurosurg. 2014; 82(1-2): $243-\mathrm{e} 256$.

20. Cohen-Inbar O, Soustiel JF, Zaaroor M. Meningiomas in the elderly, the surgical benefit and a new scoring system. Acta Neurochir(Wien). 2010;152(1):87-97.

21. Dobran M, Marini A, Nasi D, et al. Surgical treatment and outcome in patients over 80 years old with intracranial meningioma. Clin Neurol Neurosurg. 2018;167:173-176.

22. Ge Y, Liu D, Zhang Z, et al. Gamma Knife radiosurgery for intracranial benign meningiomas: follow-up outcome in 130 patients. Neurosurg Focus. 2019;46(6):E7.

23. Starke RM, Przybylowski CJ, Sugoto M, et al. Gamma Knife radiosurgery of large skull base meningiomas. J Neurosurg. 2015;122(2):363-372.

24. Steinberger J, Bronheim RS, Vempati P, et al. Morbidity and mortality of meningioma resection increases in octogenarians. World Neurosurg. 2018;109:e16-e23.

25. Loewenstern J, Aggarwal A, Pain M, et al. Peritumoral edema relative to meningioma size predicts functional outcomes after resection in older patients. Oper Neurosurg (Hagerstown). 2019;16(3):281-291.

26. Hasegawa H, Hanakita S, Shin M, et al. Single-fractionated stereotactic radiosurgery for intracranial meningioma in elderly patients: 25 -year experience at a single institution. Oper Neurosurg (Hagerstown). 2018;14(4):341-350.

27. Pollock BE, Stafford SL, Link MJ, et al. Single-fraction radiosurgery of benign cavernous sinus meningiomas. J Neurosurg. 2013;119(3):675-682.

28. Ishii K, Makita T, Yamashita H, et al. Total intravenous anesthesia with propofol is associated with a lower rate of postoperative delirium in comparison with sevoflurane anesthesia in elderly patients. J Clin Anesth. 2016;33:428-431.

29. Ekşi MŞ, Canbolat Ç, Akbaş A, et al. Elderly patients with intracranial meningioma: surgical considerations in 228 patients with a comprehensive analysis of the literature. World Neurosurg. 2019;132:e350-e365.

30. Bir SC, Konar S, Maiti TK, et al. Surgical outcomes and predictors of recurrence in elderly patients with meningiomas. World Neurosurg. 2016;90:251-261.

31. Chen Z-Y, Zheng C-H, Tang Li, et al. Intracranial meningioma surgery in the elderly (over 65 years): prognostic factors and outcome. Acta Neurochir (Wien). 2015;157(9):1549-1557.

32. Cohen-Inbar O. Geriatric brain tumor management part I: meningioma. J Clin Neurosci. 2019;67:5-9.

33. Grossman R, Mukherjee D, Chang DC, et al. Preoperative Charlson comorbidity score predicts postoperative outcomes among older intracranial meningioma patients. World Neurosurg. 2011;75(2):279-285.

34. Patil CG, Veeravagu A, Lad SP, Boakye M. Craniotomy for resection of meningioma in the elderly: a multicentre, prospective analysis from the National Surgical Quality Improvement Program. J Neurol Neurosurg Psychiatry. 2010; 81(5):502-505.

35. Slot KM, Peters JVM, Vandertop WP, et al. Meningioma surgery in younger and older adults: patient profile and surgical outcomes. Eur Geriatr Med. 2018;9(1):95-101.

36. Yamamoto J, Takahashi M, Idei M, et al. Clinical features and surgical management of intracranial meningiomas in the elderly. Oncol Lett. 2017;14(1):909-917.
37. Fatemi N, Dusick JR, de Paiva Neto MA, et al. Endonasal versus supraorbital keyhole removal of craniopharyngiomas and tuberculum sellae meningiomas. Neurosurgery. 2009; 64(5)(suppl 2):269-286.

38. Di Maio S, Akagami R. Prospective comparison of quality of life before and after observation, radiation, or surgery for vestibular schwannomas. J Neurosurg. 2009;111(4):855-862.

39. Nanda A, Thakur JD, Sonig A, Missios S. Microsurgical resectability, outcomes, and tumor control in meningiomas occupying the cavernous sinus. J Neurosurg. 2016;125(2): 378-392.

40. Nanda A, Javalkar V, Banerjee AD. Petroclival meningiomas: study on outcomes, complications and recurrence rates. $J$ Neurosurg. 2011;114(5):1268-1277.

\section{Disclosures}

Dr. Sivakumar reports receiving honoraria from Zeiss and being a consultant for Stryker. Dr. Barkhoudarian reports being a consultant for Vascular Technologies Inc. Dr. Kelly reports receiving royalties from Mizuho Inc.

\section{Author Contributions}

Conception and design: Kelly, Thakur, Mallari, Barkhoudarian. Acquisition of data: Thakur, Eisenberg, Sivakumar. Analysis and interpretation of data: Kelly, Thakur, Mallari, Eisenberg, Sivakumar, Krauss, Griffiths, Barkhoudarian. Drafting the article: Kelly, Thakur, Mallari, Corlin, Yawitz, Huang, Eisenberg, Sivakumar, Barkhoudarian. Critically revising the article: Kelly, Thakur, Mallari, Sivakumar, Krauss, Griffiths, Barkhoudarian. Reviewed submitted version of manuscript: Kelly, Thakur, Mallari, Barkhoudarian. Approved the final version of the manuscript on behalf of all authors: Kelly. Statistical analysis: Kelly, Thakur, Mallari, Barkhoudarian. Administrative/technical/ material support: Kelly, Barkhoudarian. Study supervision: Kelly, Barkhoudarian.

\section{Supplemental Information \\ Online-Only Content}

Supplemental material is available online.

Supplemental Table 1. https://thejns.org/doi/suppl/10.3171/ 2020.7.FOCUS20515.

\section{Previous Presentations}

A portion of this work was submitted for consideration in abstract form at the 14th Annual AANS/CNS Tumor Satellite Symposium, September 11-12, 2020, and has been awarded a Gold Award in the research for meningioma category.

\section{Correspondence}

Daniel F. Kelly: Pacific Neuroscience Institute, Santa Monica, CA.dkelly@pacificneuro.org. 